\title{
Towards an understanding of salient neighborhood boundaries: adolescent reports of an easy walking distance and convenient driving distance
}

\author{
Natalie Colabianchi*1, Marsha Dowda ${ }^{2}$, Karin A Pfeiffer ${ }^{3}$, Dwayne E Porter ${ }^{4}$, \\ Maria João CA Almeida ${ }^{5}$ and Russell R Pate ${ }^{2}$
}

Address: ${ }^{1}$ Department of Epidemiology and Biostatistics, University of South Carolina, 921 Assembly Street, Columbia, SC 29208, USA 2Department of Exercise Science, University of South Carolina, 921 Assembly Street, Columbia, SC 29208, USA, ${ }^{3}$ Department of Kinesiology, Michigan State University, Room 3 IM Sports Circle, East Lansing, MI 48824, USA, ${ }^{4}$ Department of Environmental Health Sciences, University of South Carolina, 921 Assembly Street, Columbia, SC 29208, USA and ${ }^{5}$ Department of Physical Education and Sports, University of Madeira, $9000-$ 390 Funchal, Madeira, Portugal

Email: Natalie Colabianchi* - colabianchi@sc.edu; Marsha Dowda - mdowda@gwm.sc.edu; Karin A Pfeiffer - kap@msu.edu; Dwayne E Porter - porter@sc.edu; Maria João CA Almeida - jalmeida@uma.pt; Russell R Pate - rpate@gwm.sc.edu

* Corresponding author

\begin{abstract}
Numerous studies have examined the association between the surrounding neighborhood environment and physical activity levels in adolescents. Many of these studies use a road network buffer or Euclidean distance buffer around an adolescent's home to represent the appropriate geographic area for study (i.e., neighborhood). However, little empirical research has examined the appropriate buffer size to use when defining this area and there is little consistency across published research as to the buffer size used. In this study, $90912^{\text {th }}$ grade adolescent girls of diverse racial and geographic backgrounds were asked to report their perceptions of an easy walking distance and a convenient driving distance. These two criterions are often used as the basis for defining one's neighborhood.

The mean easy walking distance in minutes reported by adolescent girls was 14.8 minutes $(S D=8.7)$. The mean convenient driving distance in minutes reported was 17.9 minutes $(S D=10.8)$. Nested linear multivariate regression models found significant differences in reported 'easy walking distance' across race and BMI. White adolescents reported on average almost 2 minutes longer for an easy walking distance compared to African American adolescents. Adolescents who were not overweight or at risk for overweight reported almost 2 minutes fewer for an easy walking distance relative to those who were overweight or at risk for overweight. Significant differences by urban status were found in the reported 'convenient driving distance'. Those living in non-urban areas reported on average 3.2 minutes more driving time as convenient compared to those living in urban areas. Very little variability in reported walking and driving distances was explained by the predictors used in the models (i.e., age, race, BMI, physical activity levels, urban status and SES).

This study suggests the use of a 0.75 mile buffer to represent an older female adolescent's neighborhood, which can be accessed through walking. However, determining the appropriate area inclusive of car travel should be tailored to the geographic location of the adolescent since non-urban adolescents are willing to spend more time driving to destinations. Further research is needed to understand the substantial variability across adolescent perceptions of an easy walking and convenient driving distance.
\end{abstract}




\section{Background}

There has been a dramatic increase in the number of studies that examine the association between characteristics of an adolescent's neighborhood and physical activity. While many studies have found positive associations $[1,2]$, there is surprisingly little consistency across studies in the operational definition of one's neighborhood.

Earlier research used the census tract as the basis for describing a neighborhood [3]. More recently buffers around the participant's home are used as a proxy for a neighborhood [4]. Commonly used distances for creating these buffers in the adolescent physical activity literature are 0.5-0.6 miles (800 - 1000 meters) [5-7] or a 1 mile (1500-1600 meters) buffer around the home [8-10]. However buffers as small as 0.25 miles (400 meters) [11] and as large as 5 miles (8.05 kilometers) have been used [12]. Most studies acknowledge the lack of empirical data for selecting these distances and suggest additional research. One rationale for selecting these geographies is that they correspond to an easy walking distance $[7,11]$ though little empirical evidence exists for defining an easy walking distance. Larger buffers are sometimes employed to represent a reasonable driving distance [13].

The few studies that have explicitly studied perceptions of neighborhood boundaries have been completed with adults $[14,15]$. However the perception of neighborhood boundaries for an adolescent would likely be different. Also notably absent from the literature are studies that examine differences in neighborhood boundaries across other characteristics, such as whether the person lives in an urban or rural area. This study addresses this gap by explicitly examining adolescent reports of an easy walking distance and convenient driving distance.

\section{Methods}

This study includes female adolescents recruited as part of a physical activity intervention trial $(\mathrm{N}=1655)[16]$, who also completed a physical activity recall survey, an addendum with walking and driving distance questions and whose address could be geocoded (59\%). After participants with missing covariates were deleted, the final sample included $90912^{\text {th }}$ grade adolescent girls. The sample contained nearly equal numbers of White and African American adolescents. Parental consent and adolescent assent/consent were obtained. The procedures were approved by the Institutional Review Board at the University of South Carolina.

The main outcomes in this study are reported 'easy walking distance' and 'convenient driving distance' in minutes. These outcomes were calculated from these two questions: "When you think of an 'easy walking distance', it is minutes"; and "When you think of a 'convenient driving distance', it is minutes". The distribution of these outcomes was skewed to the right and therefore all values above the $95^{\text {th }}$ percentile were recoded to the $95^{\text {th }}$ percentile.

The mean number of minutes was calculated for easy walking distance. Linear regressions, which controlled for school effects and intervention status, were completed using SAS ${ }^{\mathrm{TM}}$ version 9.1 with minutes of easy walking distance as the dependent variable and the following as independent variables: race, urban status, SES, BMI, physical activity level and age. The covariates were classified as follows: Race (White or African American); Urban status (based on participant's census block); SES (parent with $\leq$ high school versus $>$ high school education); Objectively measured BMI (at risk for overweight or overweight defined as $\geq 85^{\text {th }}$ percentile using CDC growth charts versus $<85^{\text {th }}$ percentile); Physical activity level (two or more 30-min blocks of moderate-to-vigorous physical activity per day self reported on the 3-Day Physical Activity Recall [17] versus less activity); and Age (years). Regressions were first run with each predictor variable examined separately while controlling for intervention status and school effects. Then linear regressions with all predictors examined simultaneously were run. All analyses were then repeated using 'convenient driving distance' as the outcome.

\section{Results}

The mean easy walking distance reported was 14.8 minutes (SD: 8.7). In single predictor models, significant differences were found in reported 'easy walking distance' across race $(\beta$ for white adolescents $=1.27 ; \mathrm{p}=.03$ ) and weight group ( $\beta$ for non-overweight/non-at risk for overweight $=-1.65 ; \mathrm{p}=.01)$. The multivariate analysis mirrored the single predictor models (see Table 1). White adolescents reported on average almost 2 minutes longer for an easy walking distance compared to African American adolescents. Adolescents who were not overweight or at risk for overweight reported almost 2 minutes fewer for an easy walking distance relative to those who were overweight or at risk for overweight. Age, urban status, SES and physical activity levels were not significantly associated with reported easy walking distance in these analyses.

The mean convenient driving distance reported was 17.9 minutes (SD: 10.8). In single predictor models, significant differences were found in reported 'convenient driving distance' across race $(\beta$ for white adolescents $=-1.49 ; \mathrm{p}=$ .04 ), SES ( $\beta$ for having a parent with high school education or less $=1.58 ; \mathrm{p}=.04$ ), and urban status ( $\beta$ for nonurban adolescents $=3.34 ; \mathrm{p}<.001)$. Age, BMI and physical activity levels were not significantly associated with reported convenient driving distance in the single predictor models. In the multivariate model, only urban status 
Table I: Regression analyses for the relationship between 'Easy Walking Distance' and 'Convenient Driving Distance' with demographic characteristics controlling for intervention status and with school as a random variable

\begin{tabular}{|c|c|c|c|c|}
\hline & \multicolumn{2}{|c|}{ Easy Walking Distance } & \multicolumn{2}{|c|}{ Convenient Driving Distance } \\
\hline & $\beta$ (SE) & p-value & $\beta$ (SE) & p-value \\
\hline Intercept & I.5I (8.44) & .86 & $17.26(10.46)$ & .11 \\
\hline Group (Control) & $0.63(0.69)$ & .37 & $1.27(0.72)$ & .09 \\
\hline Age & $0.75(0.47)$ & .11 & $-0.02(0.59)$ & .97 \\
\hline Race (White) & $\mathrm{I} .83(0.62)$ & .003 & $-1.23(0.76)$ & .10 \\
\hline SES (Having a parent with HS education or less) & $0.79(0.62)$ & .20 & $0.88(0.76)$ & .25 \\
\hline BMI (Not overweight or at risk for overweight)* & $-1.86(0.63)$ & .003 & $-0.86(0.78)$ & .27 \\
\hline Physical Activity (Insufficient MVPA)** & $-0.32(0.66)$ & .63 & $-0.12(0.82)$ & .88 \\
\hline Urban status (Non-urban) & $0.07(0.61)$ & .90 & $3.24(0.73)$ & $<.001$ \\
\hline
\end{tabular}

$*<85^{\text {th }}$ percentile using CDC growth charts for adolescents; $<25 \mathrm{BMI}$ for participants old enough to be classified as adults

** Zero or one 30-min blocks of physical activity at $\geq 3$ METS

remained significantly associated with reported convenient driving distance (see Table 1). Those living in nonurban areas reported on average 3.2 minutes more driving time as convenient compared to those living in urban areas.

There were large standard deviations for both easy walking distance and convenient driving distance. A model concordance correlation coefficient (MCCC) was calculated for the two models. The MCCC is similar to an $\mathrm{R}^{2}$ in a linear regression but is appropriate for mixed models in that it accounts for non-independent responses [18]. The MCCC was 0.06 for both multivariate models indicating that very little variability in reported walking and driving distances was explained by the predictors in these models.

\section{Discussion}

On average, female adolescents reported that an easy walking distance was about 15 minutes. Assuming a walking speed of 80 meters per minute or 3 miles per hour [19], a 15 minute walk translates to 1184 meters or approximately 0.75 miles. However there was substantial variation across adolescent reports that was not explained by the predictor variables included in the models. Consequently, while a 15 minute walk may be an easy distance for many older female adolescents, further research is needed to understand the great variability that remains across adolescents. The mean reported convenient driving distance was 17.9 minutes. Assuming an average driving speed of 55 kilometers per hour or 35 miles per hour, a 17.9 minute drive translates to 16.4 kilometers or approximately 10 miles.

Non-urban adolescents reported a longer distance as convenient for driving compared to urban adolescents but there was not a significant difference in the reported easy walking distance between urban and non-urban adoles- cents. This suggests that non-urban adolescents may be willing to drive farther however there may be a common limit to how far adolescents are willing to walk. The significant differences in an easy walking distance by race may be confounded with the distance needed to travel to get to destinations as recent research suggests that the distance adults are willing to walk may depend on the destination [20]. At present, it is not known why adolescents who were not overweight or at risk for overweight would report a shorter distance as 'easy' though it could be related to a quicker walking pace which would reduce the amount of time it would take to walk the same distance.

This study is the first to explicitly examine the distance that adolescents perceive as an easy walking distance and convenient driving distance. A study of parental reports of an appropriate walking distance for their children reported that $1.5 \mathrm{~km}$ (about 1 mile) for children 5-6 and $1.6 \mathrm{~km}$ for children $10-12$ years of age were considered appropriate [21]. Other researchers have attempted to determine the appropriate buffer size by investigating the persistence of a relationship between physical activity and the built environment across various buffers $[8,9,22]$ or have examined threshold distances [23]. These studies have generally supported buffers ranging from 0.25 to 1 mile.

Since this study examined only females in $12^{\text {th }}$ grade in one southeastern US state, further research should be completed to understand what constitutes an 'easy walking distance' and 'convenient driving distance' for younger adolescents, boys and adolescents in different locations. Further, adolescents were asked to report an easy walking distance and convenient driving distance though adolescents may need to or choose to walk further than an easy distance or drive further than a convenient distance for a variety of reasons. In addition, in translating the reported 
minutes of an easy walking distance and convenient driving distance into an actual distance, a constant walking rate and driving rate was assumed for all adolescents. Finally, the buffers described utilized the mean minutes reported. Shorter times were preferred by over half the sample and under half of participants reported longer times. Caution should be taken when assigning any single buffer across all adolescents as there is great variability across definitions.

\section{Conclusion}

This study supports the postulation that 0.75 miles is an appropriate walking distance for older adolescent girls. The distance representing a convenient driving distance should be tailored to the geographic location of the adolescent since non-urban adolescents found longer driving times more convenient.

\section{Competing interests}

The author(s) declare that they have no competing interests.

\section{Authors' contributions}

$\mathrm{NC}, \mathrm{KP}, \mathrm{MA}, \mathrm{MD}, \mathrm{DP}$ and RP contributed to the conception and design of the study. RP originated the study and supervised all aspects of its implementation. MD served as data manager and completed the analyses. All authors were involved the interpretation of the data and the drafting and revision of content. All authors read and approved the final manuscript.

\section{Acknowledgements}

This study was funded by a grant from the National Heart, Lung and Blood Institute (ROIHL057775).

\section{References}

I. Davison KK, Lawson CT: Do attributes in the physical environment influence children's physical activity? A review of the literature. Int J Behav Nutr Phys Act 2006, 3:19.

2. Ferreira I, van der Horst K, Wendel-Vos W, Kremers S, van Lenthe FJ, Brug J: Environmental correlates of physical activity in youth - a review and update. Obes $\operatorname{Rev} 2007,8(2): 129-154$.

3. Mujahid MS, Diez Roux AV, Morenoff JD, Raghunathan T: Assessing the measurement properties of neighborhood scales: from psychometrics to ecometrics. Am J Epidemiol 2007, 165(8):858-867.

4. Porter DE, Kirtland KA, Neet MJ, Williams JE, Ainsworth BE: Considerations for using a geographic information system to assess environmental supports for physical activity. Prev Chronic Dis 2004, I(4):A20.

5. Braza M, Shoemaker $W$, Seeley A: Neighborhood design and rates of walking and biking to elementary school in 34 California communities. Am J Health Promot 2004, 19(2): I 28-136.

6. Kerr J, Rosenberg D, Sallis JF, Saelens BE, Frank LD, Conway TL: Active commuting to school: Associations with environment and parental concerns. Med Sci Sports Exerc 2006, 38(4):787-794.

7. Timperio A, Ball K, Salmon J, Roberts R, Giles-Corti B, Simmons D, Baur LA, Crawford D: Personal, family, social, and environmental correlates of active commuting to school. Am J Prev Med 2006, 30(I):45-5I.

8. Norman G], Nutter SK, Ryan S, Sallis JF, Calfras KJ, Patrick K: Community design and access to recreational facilities as corre- lates of adolescent physical activity and body mass index. Phys Act Health 2006, SuppI I Vol 3:SI I8-28.

9. Cohen DA, Ashwood JS, Scott MM, Overton A, Evenson KR, Staten LK, Porter D, McKenzie TL, Catellier D: Public parks and physical activity among adolescent girls. Pediatrics 2006, I I 8(5): el 38I-9.

10. Jago R, Baranowski T, Baranowski JC: Observed, GIS, and selfreported environmental features and adolescent physical activity. Am J Health Promot 2006, 20(6):422-428.

I I. Jago R, Baranowski T, Zakeri I, Harris M: Observed environmental features and the physical activity of adolescent males. Am J Prev Med 2005, 29(2):98-104.

12. Gordon-Larsen P, Nelson MC, Page P, Popkin BM: Inequality in the built environment underlies key health disparities in physical activity and obesity. Pediatrics 2006, II 17(2):417-424.

13. Kirtland KA, Porter DE, Addy CL, Neet MJ, Williams JE, Sharpe PA, Neff LJ, Kimsey CD Jr., Ainsworth BE: Environmental measures of physical activity supports: perception versus reality. $\mathrm{Am} J$ Prev Med 2003, 24(4):323-331.

14. Coulton CJ, Korbin J, Chan T, Su M: Mapping residents' perceptions of neighborhood boundaries: a methodological note. Am J Community Psychol 200I, 29(2):37I-383.

15. Lee BA, Campbell KE: Common ground? Urban neighborhoods as survey respondents see them. Soc Sci $Q$ 1997, 78:922-936.

16. Pate RR, Ward DS, Saunders RP, Felton G, Dishman RK, Dowda M: Promotion of physical activity among high-school girls: a randomized controlled trial. Am J Public Health 2005, 95(9): $1582-1587$.

17. Pate RR, Ross R, Dowda M, Trost SG, Sirard J: Validation of a three-day physical activity recall instrument in female youth. Pediatr Exerc Sci 2003, 15:257-265.

18. Vonesh EF, Chinchilli VM, Pu K: Goodness-of-fit in generalized nonlinear mixed-effects models. Biometrics 1996 52(2):572-587.

19. Perry J: Gait analysis: normal and pathological function. Thorofare, NJ , Slack Incorporated; 1992.

20. McCormack GR, Giles-Corti B, Bulsara M, Pikora TJ: Correlates of distances traveled to use recreational facilities for physical activity behaviors. Int J Behav Nutr Phys Act 2006, 3:18.

21. Timperio A, Crawford D, Telford A, Salmon J: Perceptions about the local neighborhood and walking and cycling among children. Prev Med 2004, 38(I):39-47.

22. McCormack GR, Giles-Corti B, Bulsara M: The relationship between destination proximity, destination mix and physical activity behaviors. Prev Med 2007.

23. Moudon AV, Lee C, Cheadle AD, Garvin C, Johnson D, Schmid TL, Weathers RD, Lin L: Operational definitions of walkable neighborhood: theoretical and empirical insights. J Phys Act Health 2006, SuppI I Vol 3:S99-II7.

Publish with Biomed Central and every scientist can read your work free of charge

"BioMed Central will be the most significant development for disseminating the results of biomedical research in our lifetime. "

Sir Paul Nurse, Cancer Research UK

Your research papers will be:

- available free of charge to the entire biomedical community

- peer reviewed and published immediately upon acceptance

- cited in PubMed and archived on PubMed Central

- yours - you keep the copyright 